\title{
Identification of RAPD markers associated with the presence of $B$ chromosomes in maize
}

\author{
C. GOURMET* \& A. LANE RAYBURN \\ Department of Crop Sciences, University of Illinois at Urbana-Champaign, 320 ERML, 1201 West Gregory Drive, \\ Urbana, IL 61801, U.S.A.
}

\begin{abstract}
DNA isolated from Black Mexican sweet maize populations segregating for the presence of B chromosomes was used for PCR amplifications of 320 RAPD primers. Seventeen primers produced detectable polymorphisms between populations known to carry B chromosomes and populations devoid of $\mathrm{B}$ chromosomes. To ensure that the primers which generated a polymorphic band were indeed identifying B chromosomes, five Arizona Indian corn populations, three tetraploid corn populations and two High Loss corn lines differing in their B chromosome composition were analysed. Four primers were selected to screen these maize populations. Root tip counts were performed on the lines to confirm the association of the RAPD markers to the presence of $\mathrm{B}$ chromosomes.
\end{abstract}

Keywords: B chromosomes, polymorphism, RAPD markers, Zea mays.

\section{Introduction}

$\mathrm{B}$ chromosomes in maize are chromosomes that are different from normal A chromosomes with respect to various morphological and behavioural characteristics (Rieger et al., 1976). B chromosomes are largely heterochromatic chromosomal segments that contain few if any genes and appear to have only minor effects on plant viability and phenotype when present in small numbers. However, when present in large numbers, B chromosomes can have a devastating effect on maize growth and development (Randolph, 1941). B chromosomes have no homology with A chromosomes and therefore do not pair with any $\mathrm{A}$ chromosomes during meiosis. In maize, $\mathrm{B}$ chromosomes undergo nondisjunction and preferential fertilization events which result in their ability to vary in number generation to generation (Carlson, 1988). Maize populations carrying B chromosomes may therefore contain plants with no B chromosomes, plants with few B chromosomes and plants with many B chromosomes. For instance, Porter \& Rayburn (1990) found plants in several south-western Indian maize populations that varied with respect to $\mathrm{B}$ chromosome number. Could

\footnotetext{
${ }^{*}$ Correspondence.
}

molecular markers be used to identify plants and/or populations with $\mathrm{B}$ chromosomes?

Translocations between B and A chromosomes have been produced by Roman $(1947,1948)$ and Beckett (1978). Recently, several researchers have been interested in elucidating the role of the $B$ chromosomes in the mechanism of the B-A translocations using techniques such as Southern blot analyses and chromosomal in situ hybridizations (Birchler et al., 1990; Carlson \& Roseman, 1992; Alfenito \& Birchler, 1993). In 1990, Birchler et al. attempted to determine whether recombination occurred in the B chromosomes. Lacking the necessary molecular markers on the B chromosomes, they constructed a set of A-B-A chromosomes. They used translocations that are broken in opposite arms of the B chromosomes and in different A chromosome arms. To be useful, these constructs must attach known genetic markers to the B chromosomes. The choice of material necessary to conduct the experiment relies on cytological and morphological examinations of the plant material. The addition of molecular markers identifying the $B$ chromosomes would provide an additional tool for marking the B-A translocations.

Since the discovery by Williams et al. (1990) and Welsh \& McClelland (1990), that arbitrary random 
decamer primers could reveal polymorphic DNA profiles between individuals using the polymerase chain reaction, this molecular technique termed RAPD for 'randomly amplified polymorphic DNA' has been used extensively to study plant and animal populations. Iqbal \& Rayburn (1995) used RAPDs to identify rye introgression into wheat background. Devos \& Gale (1992) linked a RAPD amplified fragment to chromosome 4 of barley (Hordeum vulgare cv. Betzes) in wheat (Chinese spring) background. Similarly, King et al. (1993) identified RAPD markers specific for chromosome 5E for Thinopyrum bessarabicum in a wheat/alien recombinant.

The purpose of this study was to find RAPD markers that identify the presence of the B chromosomes in maize populations of diverse backgrounds. Such markers would provide researchers, devoted to investigate the role and implication of the $\mathrm{B}$ chromosomes in the maize genome with an additional tool to facilitate their task. The markers would also aid in the development of a RAPD saturation map of the $\mathrm{B}$ chromosomes.

\section{Materials and methods}

\section{Genetic stocks}

Two seed stocks of Black Mexican sweet corn (BMSC), five seed stocks of Arizona Indian corn (AIC), three seed stocks of tetraploid (4N) corn, and two seed stocks of High Loss corn (HLC) were obtained from the Maize Genetic Cooperative at the University of Illinois at Urbana-Champaign. One BMSC stock contains B chromosomes (referred to as BMSC-B) and one lacks them (referred to as BMSC-A). The five AIC populations (PI 218174 A, PI 218174 B, PI 218179, PI 218186 A, and PI 218186 B) are known to contain plants having B chromosomes. The $4 \mathrm{~N}$ populations are (i) $\mathrm{N} 107 \mathrm{C}$, referred to as Alex Syn B (does not carry B chromosomes), (ii) $\mathrm{N} 102 \mathrm{E}$, referred to as $4 \mathrm{~N}+\mathrm{B}$ chromosomes, and (iii) N102EA, resulting from a cross between Alex Syn B and N102E (designated to carrying B chromosomes). One HLC line contains B chromosomes (Rhoades $39840^{\text {sib }}$ ) and we will refer to it as HLC-B and one lacks B chromosomes (Rhoades 39839 selfed) and it will be referred to as HLC-A. A total of 58 plants representing ten genetically distinct backgrounds were examined for the presence of $\mathrm{B}$ chromosomes.

\section{DNA isolation}

Seeds were planted at room temperature in small pots containing a mixture of soil and vermiculite.
The plants were exposed to Gro Lux Fluorescent lights for 2 weeks, at which time leaves were harvested and stored at $-80^{\circ} \mathrm{C}$. Genomic DNA was then extracted from the leaves by the method of Rogers \& Bendich (1988) with some modifications. Leaves were ground into a very fine powder in liquid nitrogen and transferred to an Eppendorf tube. Five hundred microlitres of hot $\left(65^{\circ} \mathrm{C}\right) 2 \times \mathrm{CTAB}$ ( 2 per cent CTAB (w/v), 100 mm Tris- $\mathrm{HCl}(\mathrm{pH} \mathrm{8.0),} 1.4 \mathrm{~m}$ $\mathrm{NaCl}$ and 1 per cent PVP (polyvinylpyrrolidone) MW 40000 ) was added. The mixture was kept at $65^{\circ} \mathrm{C}$ for $4 \mathrm{~min}$. Then, $500 \mu \mathrm{L}$ of chloroform/isoamyl alcohol $(24: 1)$ was added. The emulsion was centrifuged at $11000 \mathrm{~g}$ for $30 \mathrm{~s}$. The aqueous phase was transferred to another tube and $1 / 10$ volume of $10 \times$ CTAB $(10$ per cent CTAB $(w / v), 0.7 \mathrm{~m} \mathrm{NaCl})$ was added, mixed and treated with an equal volume of chloroform/isoamyl alcohol. After 40 s centrifugation, the aqueous phase was again removed. To the aqueous phase, an equal volume of $1 \times \mathrm{CTAB}$ (precipitation buffer) (1 per cent CTAB (w/v), 50 mм Tris-HCl (pH 8.0), 10 mм EDTA (pH 8.0)) was added to precipitate DNA. The DNA was pelleted by centrifugation (10-40 s) and rehydrated in high salt TE buffer (10 mM Tris- $\mathrm{HCl}(\mathrm{pH} 8.0), 1 \mathrm{~mm}$ EDTA ( $\mathrm{pH} \mathrm{8.0),} 1 \mathrm{~m} \mathrm{NaCl}$ ). The DNA was reprecipitated with ethanol (chilled at $-20^{\circ} \mathrm{C}$ ) and centrifuged at $11000 \mathrm{~g}$ for $15 \mathrm{~min}$. The pellet was washed with 80 per cent cold ethanol and again spun for 5 min. The pellet was air dried and rehydrated in $0.1 \times$ TE $(1.0 \mathrm{~mm}$ Tris-HCl $(\mathrm{pH} 8.0), 0.1 \mathrm{~mm}$ EDTA $(\mathrm{pH} 8.0))$ and treated with RNAse $(1 \mu \mathrm{L}$ of stock RNAse $/ 20 \mu \mathrm{L}$ of DNA solution) for $1 \mathrm{~h}$ at $37^{\circ} \mathrm{C}$. After treatment with RNAse, 1/10 volume of $2 \mathrm{M}$ $\mathrm{NaCl}$ (or of $3 \mathrm{M} \mathrm{Na}$ acetate), along with two volumes of cold 100 per cent ethanol, were added to precipitate the DNA. The DNA was pelleted by centrifugation $(5 \mathrm{~min})$, washed once more with 70 per cent ethanol and air dried before being rehydrated in $0.1 \times$ TE buffer. Quantification of DNA was accomplished by analysing samples of the DNA extracts with a spectrophotometer (UV $160 \mathrm{U}$ - UV visible recording spectrophotometer, SHIMADZU) using UV absorbance at $260 \mathrm{~nm}$. All samples of DNA were then diluted to a concentration $12.5 \mathrm{ng}$ $\mu \mathrm{L}^{-1}$.

\section{DNA amplification}

Several primers were used in single primer amplification of RAPD sequences. Sixteen sets of 20 random decamer oligonucleotides (OPA, OPD, OPE, OPG, OPH, OPJ, OPK, OPL, OPM, OPN, OPO, OPP, OPR, OPS, OPU and OPY) were 
purchased from Operon Technologies (Alameda, CA, USA).

PCR reactions were performed according to the method of Williams et al. (1990) with some modifications. Reaction volumes were $25 \mu \mathrm{L}$ overlaid with two drops of light mineral oil (Sigma Chemicals). Each reaction consisted of $0.2 \mu \mathrm{L}$ (1 U) Taq polymerase (Bethesda Research Laboratories), $2.5 \mu \mathrm{L}$ $10 \times \mathrm{Mg}$-free Taq polymerase activity buffer, $2.5 \mu \mathrm{L}$ of $25 \mathrm{mM} \mathrm{MgCl}_{2}$ and $2 \mu \mathrm{L}$ of $2.5 \mathrm{~mm}$ deoxyribonucleoside-5'-triphosphates (dNTPs), all purchased from Perkin Elmer Corporation, CT, $1 \mu \mathrm{L}$ of 0.001 per cent gelatin (Sigma Chemicals), $5.3 \mu \mathrm{L} \mathrm{H}_{2} \mathrm{O}, 2$ $\mu \mathrm{L}$ of primer $\left(15 \mathrm{ng} \mu \mathrm{L}^{-1}\right)$ and $4 \mu \mathrm{L}$ of genomic DNA.

Amplifications were conducted in a Hybaid Thermocycler for 40 cycles with the first step at $94^{\circ} \mathrm{C}$ for $3 \mathrm{~min}$, followed by 40 cycles of $94^{\circ} \mathrm{C}$ for $1 \mathrm{~min}, 36^{\circ} \mathrm{C}$ for $1 \mathrm{~min}, 72^{\circ} \mathrm{C}$ for $2 \mathrm{~min}$, with a ramp of $3 \mathrm{~s} / 1^{\circ} \mathrm{C}$ between annealing and extension steps. After 40 cycles, there was a final extension step of $10 \mathrm{~min}$ at $72^{\circ} \mathrm{C}$. Before removing the reaction product, it was held at $25^{\circ} \mathrm{C}$ for a minimum of $5 \mathrm{~min}$. The PCR products were separated on a 1.2 per cent agarose gel in TBE (Tris-borate EDTA) buffer. Amplified products were detected by staining with ethidium bromide and visualized by illumination with ultraviolet light. A $1 \mathrm{~kb}$ DNA ladder (BRL) was used as a size marker.

\section{Chromosome counts}

Root tip chromosome counts were performed as follows. Root tips were harvested when the seedlings were 1 week old, rinsed in distilled water and treated for $2 \mathrm{~h}$ in a 0.05 per cent 8 -hydroxyquinoline solution and placed at $32^{\circ} \mathrm{C}$ in a dark chamber. The tips were then rinsed with distilled water and fixed in alcohol-acetic acid $(3: 1)$ for $24 \mathrm{~h}$ at $4^{\circ} \mathrm{C}$. The root tips were then placed in 70 per cent ethanol and stored at $4^{\circ} \mathrm{C}$ for at least 1 week before being used to count the number of chromosomes. To prepare the root tip squashes, the roots were transferred to a glass vial containing $1 \mathrm{~mL}$ of acetocarmine. The acetocarmine was then heated to a light boil, after which the root tips were placed on a microscope slide with a cover slip and then squashed with thumb pressure.

\section{Results and discussion}

DNA samples from four BMSC-A and four BMSC$\mathrm{B}$ plants were used as the templates for the amplification of RAPD markers. A total of 320 different random decamer oligonucleotide primers were used to screen the plants for polymorphism. Fifty-eight primers produced detectable polymorphisms between plants carrying $\mathrm{B}$ chromosomes and plants without $\mathrm{B}$ chromosomes. Among the 58 primers, 17 primers (OPA-7, OPA-11, OPA-16, OPA-19, OPA-20, OPG-6, OPH-9, OPH-12, OPJ-14, OPK-1, OPK-16, OPL-8, OPN-6, OPO-3, OPO-19, OPR-11 and OPS-2) revealed the most consistent amplification products and were selected for further studies. Each primer produced one specific polymorphic amplification fragment, with the exception of OPK-1 which produced two specific polymorphic amplification fragments. An example of the polymorphism detected between the BMSC-A and BMSC-B plants is shown in Fig. 1.

To ensure that the primers which generated a polymorphic band in the BMSC-B plants were indeed identifying $\mathrm{B}$ chromosomal segments and not small genomic differences between the two seed stocks of BMSC (BMSC-A and BMSC-B), additional maize populations segregating for the presence of $\mathrm{B}$ chromosomes were included in the study. These consisted of five Arizona Indian corn populations and three tetraploid corn populations, and additional BMSC plants originating from a third seed stock. Also, two High Loss corn lines, one with $B$ chromosomes (HLC-B) and one without B chromosomes (HLC-A) were added to the study. Four primers (OPG-06, OPL-08, OPK-01 and OPK-16) out of the original selection were chosen to amplify the DNA of these additional populations.

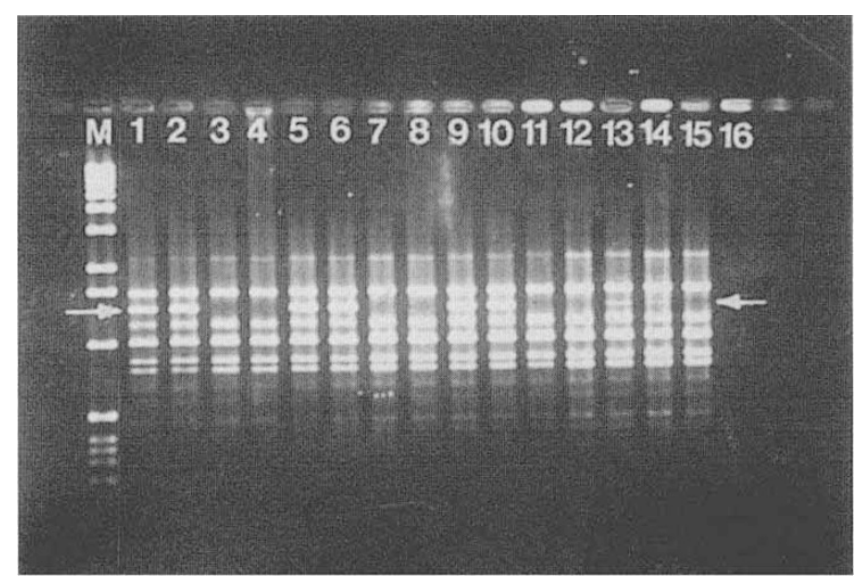

Fig. 1 Amplification profile of Black Mexican sweet corn with $\mathrm{B}$ chromosomes (lanes 1, 2, 5, 6, 9, 10, 13 and 14) and without $\mathrm{B}$ chromosomes (lanes $3,4,7,8,11,12,15$ and 16) using OPG-06 primer. Arrow indicates B chromosomes specific OPG-06 marker. M:1 kb DNA ladder (BRL). 
For the five Arizona Indian corn populations, a total of 21 plants were tested. Only PI 218174 B showed positive results. Three plants out of four tested from PI 218174 B showed a band corresponding to the presence of $\mathrm{B}$ chromosomes. This was true for all four primers selected. The root count revealed for the four plants 20,23, 24 and 26 chromosomes, therefore confirming the association of the band to the presence of $\mathrm{B}$ chromosomes. None of the plants that was devoid of the B chromosomes RAPD band was observed to have B chromosomes cytologically.

For the three tetraploid corn populations, four plants were tested from each population. Only one population (N102E) showed positive results. All four plants tested from that population showed a band corresponding to the presence of $\mathrm{B}$ chromosomes. This was true for all primers selected. An example can be seen with primer K-16 in Fig. 2. The root count for each plant revealed 42 chromosomes. No band showed up for the population $\mathrm{N} 107 \mathrm{C}$ which is labelled as not carrying B chromosomes. No plant from the population N102EA showed a band associated with the $\mathrm{B}$ chromosomes, although the population was labelled as carrying $\mathrm{B}$ chromosomes. The reason may lie in the fact that in the pollen grains of Zea maize, the presence of $\mathrm{B}$ chromosomes will cause nondisjunction at the second mitotic division with great frequency (50-100 per cent) (Carlson,

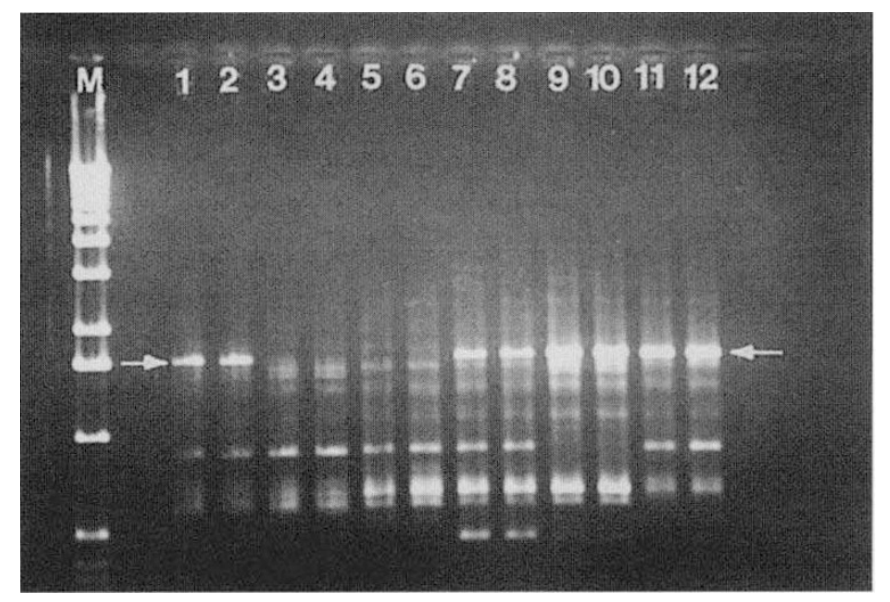

Fig. 2 Amplification profile of tetraploid corn with B chromosomes (lanes 7, 8, 13 and 14-population N102E) and without B chromosomes (lanes 5, 6, 11 and 12-population $\mathrm{N} 107 \mathrm{C}$; lanes 9, 10, 15 and 16-population N102EA), and of Black Mexican sweet corn with B chromosomes (lanes 1 and 2) and without B chromosomes (lanes 3 and 4) using OPK-16 primer. Arrow indicates B chromosomes specific marker. M:1 kb DNA ladder (BRL).
1988). If the second pollen mitosis begins with one $B$ chromosome, nondisjunction will transmit two Bs to one sperm and zero Bs to the other. Although it has been shown that a B-containing sperm preferentially fertilizes the egg, it is possible that the seeds from the population N102EA resulted from the fertilization of an egg by a sperm devoid of $\mathrm{B}$ chromosomes, therefore resulting in $F_{1}$ and $F_{2}$ seeds with no $B$ chromosomes. Confirming the RAPD results, the root count revealed a count of only 40 chromosomes for all four plants tested from the population N102EA. It is important to note that by examining only four plants from the population N102EA, we may have missed plants carrying $\mathrm{B}$ chromosomes in different numbers; however, we have determined with confidence that the root count of the four plants tested confirmed the RAPD results.

For the HLC stocks, two plants were tested from each stock. The HLC-B line showed a band associated with the presence of $\mathrm{B}$ chromosomes and the HLC-A line (without B chromosomes) showed no band present. This was true for all four primers tested. An example can be seen with primer K-16 in Fig. 3. The root counts for HLC-B plants were 24 whereas for the HLC-A plants only 20 chromosomes were present.

Thirteen additional plants segregating for the presence of B chromosomes were tested. These BMSC plants originated from a different seed stock than the seed stock previously used. All 13 plants showed the presence of a band compared to a known BMSC plant without B chromosomes.

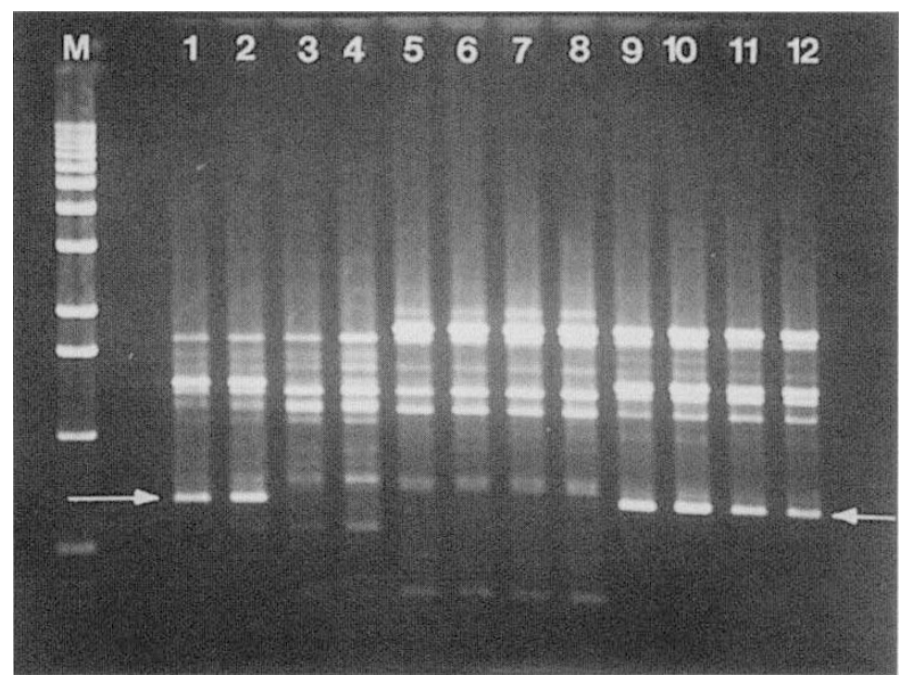

Fig. 3 Amplification profile of High Loss corn with B chromosomes (lanes 1, 2, 9, 10, 11 and 12) and without $B$ chromosomes (lanes 3, 4, 5, 6, 7 and 8) using OPK-16 primer. Arrow indicates B chromosomes specific marker. M:1 kb DNA ladder (BRL). 
Presence of B chromosomes was confirmed by either cytological or flow cytometric observation.

In conclusion, maize populations segregating for the presence of $\mathrm{B}$ chromosomes were analysed by RAPDs. Several markers associated with the presence of B chromosomes were identified. Polymorphic bands identifying $\mathrm{B}$ chromosomes were confirmed by root tip counts. The availability of RAPD markers identifying B chromosomes will provide researchers with an additional tool to conduct various types of research on the $B$ chromosomes.

\section{References}

ALFENITO, M. R. AND BIRCHLER, J. A. 1993. Molecular characterization of a maize $B$ chromosome centric sequence. Genetics, 135, 589-597.

BECKETT, J. B. 1978. B-A translocations in maize. Crit. Rev. Genet., 12, 5.

BIRCHLER, J. A., CHALFOUN, D. J. AND LEVIN, D. M. 1990. Recombination in the $B$ chromosome of maize to produce A-B-A chromosomes. Genetics, 126, 723-733.

CARLSON, w. R. 1988. B chromosomes as a model system for nondisjunction. In: Vig, B. and Sanberg, A. A. (eds) Aneuploidy, Part B: Induction and Test Systems, pp. 199-207. Alan R. Liss, New York.

CARLSON, W. R. AND ROSEMAN, R. R. 1992. A new property of the maize $B$ chromosome. Genetics, 131, 211-223.

DEVOS, K. M. AND GALE, M. D. 1992. The use of random amplified polymorphic DNA markers in wheat. Theor. Appl. Genet., 84, 567-572.
IQBAL, M. J. AND RAYBURN, A. L. 1995. Identification of the $1 \mathrm{RS}$ rye chromosomal segment in wheat by RAPD analysis. Theor. Appl. Genet., 91, 1048-1053.

KING, 1. P., PURDUE, K. A., REZANOOR, H. N., KOEBNER, R. M. D., MILLER, T. E., READER, S. M. AND NICHOLSON, P. 1993. Characterization of Thinopyrum bessarabicum chromosome segments in wheat using random amplified polymorphic DNAs (RAPDs) and genomic in situ hybridization. Theor. Appl. Genet., 86, 895-900.

PORTER, H. L. AND RAYBURN, A. L. 1990. B-chromosome and C-band heterochromatin variation in Arizona maize populations adapted to different altitudes. Genome, 33, 659-662.

RANDOLPH, L. F. 1941. Genetic characteristics of the B chromosomes in maize. Genetics, 26, 608-631.

RIEGER, R., MICHAELIS, A. AND GREEN, M. M. 1976. In: Glossary of Genetics and Gytogenetics. Classical and Molecular, fourth completely revised edition, pp. 49-50. Springer, Berlin.

ROGERS, O. S. AND BENDICH, A. J. 1988. Extraction of DNA from plant tissue. In: Glevin, S. B. and Schilperoort, R. A. (eds) Plant Molecular Biology Manual. Kluwer Academic Publishers, Dordrecht.

ROMAN, H. 1947. Mitotic nondisjunction in the case of interchanges involving the B-type chromosome in maize. Genetics, 32, 391.

Roman, H. 1948. Directed fertilization in maize. Proc. Natl. Acad. Sci. U.S.A., 34, 36-42.

WELSH, J. AND MCCLELLAND, M. 1990. Fingerprinting genomes using PCR with arbitrary primers. Nucl. Acids Res., 18, 7213-7218.

WILLIAMS, J. G. K., KUBELIK, A. R., LEVAK, K. J., RAFALSKI, J. A. AND TINGEY, S. V. 1990. DNA polymorphism amplified by arbitrary primers are useful as genetic markers. Nucl. Acids Res., 18, 6531-6535. 